\title{
The Fertility Decline in India's Kerala State: A Unique Example of Below Replacement Fertility in a High Fertility Country
}

\author{
M. V. George \\ Adjunct Professor \\ Departments of Global Health, and Sociology \\ Emory University \\ Atlanta, Georgia, USA \\ Department of Sociology \\ University of Alberta \\ Edmonton, Alberta, Canada \\ E-mail: moolamattomgeorge@yahoo.com
}

\begin{abstract}
This paper attempts to fill a gap in an updated study of the rapid fertility decline in Kerala, which has evoked world wide interest, using historical and recent data from direct and indirect sources. The three determinants of fertility decline - changes in age at marriage; the use of effective family planning methods as a result of the state's aggressive family planning program; and the unique Kerala characteristics - have contributed to the fall in fertility. Additional insights are provided by comparing this with similar fertility decline in six countries of the region.
\end{abstract}

Key Words: fertility decline, determinants, age at marriage, family planning 


\section{Résumé}

Cet article essaye de remplir une lacune dans une étude récente sur le déclin rapide de la fécondité au Kérala - une étude qui a suscité un intérêt dans le monde entier - en nous appuyant sur des données historique et récente provenant de sources directes et indirectes. Les trois déterminants du déclin de la fécondité - les changements dans l'âge minimum de nuptialité, l'utilisation de méthodes effectives de contraception à la suite d'une campagne agressive de planification familiale, et les caractéristiques uniques au Kérala - ont contribués à la chute du taux de fécondité. D'autres idées et théories sont offertes en comparant la situation au Kérala à six autres pays dans la région qui subissent aussi un déclin de fécondité similaire.

Mots-clés: Déclin de la fécondité, âge minimum de nuptialité, planification familia

\section{Introduction}

Kerala is a small state of India. ${ }^{1}$ It differs greatly from other states with distinct features, in that the demographic transition from high to low birth and death rates has occurred in a short period of time without the requisite conditions associated with the classical demographic transition (Coale 1973; Bongaarts 1978; Stokes 1995; United Nations 1990). It is estimated that in about 12 years, 1961-1971 to 1976-1980, the total fertility rate (TFR) in Kerala had fallen by over 32\% from 5.0 to 3.4, and continued its decline ever since that time. By 1986-1990 it had fallen to the replacement level of 2.1 and further fell to 1.93 in 2005-2006. The rapidity and magnitude of such a decline in TFR was a record because it happened without adequate economic development unlike in many Western and South-East Asian countries such as China, Hong Kong, People's Republic of Korea, Republic of Korea, Thailand, Singapore, and Sri Lanka. This unique experience in fertility decline in Kerala has been a subject of great interest to demographers and others, and evoked world wide attention as it poses to challenge the credibility of the demographic transition theory primarily based on the experience of Western European countries. A few scholars have even depicted this 
The Fertility Decline in India's Kerala State: A Unique Example of Below Replacement Fertility in a HIgh Fertility Country

experience as a paradox or anomaly in reducing fertility as it happened despite low per capita income, low levels of industrialization, urbanization and nutrition (Ratcliffe 1978; Zachariah 1984). A revisit and examination of such an abrupt fertility decline is useful not only from a policy perspective, but also for expanding the horizon of fertility theory.

What are the factors/determinants that contributed to the rapid decline in fertility in Kerala from the 1960s? Fertility reductions can occur due to two main factors. They are: (1) increase in age at marriage and the corresponding reduction in the proportion of women married in the reproductive ages; and (2) rise in family planning by the use of contraceptive methods. These are two out of the four proximate variables that can explain variations in fertility (Bongaarts 1978). Data on the other two variables, viz., induced abortion (medical termination of pregnancy) and lactation infecundability are not easily available and are considered not important for this study. The operation of these factors is conditioned by a multiplicity of socio-economic, demographic and political factors and developments that influence them.

This paper attempts to fill a gap in an updated study on Kerala's fertility decline using recent and current data, including the results from the three National Family Health surveys (NFHS-1; NFHS-2 and NFHS3 ), and contributes to the existing body of knowledge on the subject. It is also a revisit and an overview of Kerala fertility trends and patterns as the present author has done pioneering research on fertility in Kerala (see George 1959).

The study provides first a description of Kerala's unique characteristics followed by a brief historical account of demographic components and changes in Kerala as background to the analysis of fertility decline. Second, it examines the fertility trends, pattern and factors of fertility decline in Kerala using historical and current data from direct and indirect sources. The indirect sources are the data and findings of existing studies on the subject (Zachariah 1984; Zachariah et al. 1992; Zachariah and Kurup 1984; Nag 1989; Ratclife 1978; Bhat and Rajan 1990; Nair 1986; and Krishnan 1970). A passing review of these studies is made while discussing or using the data and findings from them. Much of the findings used in the present study are from the two comprehensive reports on Kerala's fertility decline, based on the Kerala fertility survey by the World Bank: Zachariah 1984; and Zachariah et al. 1992 (both are basically the same). Third, it provides some additional insights by comparing Kerala's fast decline with other countries in Asia that have undergone similar demographic transition. Fourth, it touches on the main policy implications of its findings and the need for future research on the dynamics and factors of the recent fertility decline in other Indian states. 
And fifth, it indicates the prospect of continued low fertility in Kerala, and some notable effects of the fertility decline.

\section{Unique Characteristics of Kerala}

Kerala State, situated in the South-West corner of India, is unique in several respects. The following is a brief description of its unique geographic, socio-economic and political features and differences compared with the other states that have played a major role in achieving its demographic transition with low mortality and fertility levels.

Kerala, known as the land of coconut trees, is a narrow strip of land area extending from north to south, about 585 kilometers, and from the Western Ghats (high mountains) in the east to the Arabian Sea in the west. It is about 120 kilometers at the widest point, with a total area of 38,863 sq. kilometers. With a total population slightly above that of Canada's (31.8 million in 2001), it has a density of 819 , the third highest among the Indian states (Table 1).

Despite the tropical weather with fertile land and abundant water supply, Kearala has always remained a food deficit area for two reasons. One, the man land ratio is very small; the cultivable land per person is only 0.21 acres. Second, there is more emphasis on more profitable cash crops like rubber, coconuts, etc. than rice production. It has a variety of good transportation facilities - waterways, railways and roadways connecting even the remote rural areas. Kerala is the only state in India that has road connections to all its villages.

The layout of its villages is quite distinct, in that the houses are scattered with courtyards on each side and surrounded by evergreen tropical vegetation unlike the village system of clustered houses in other parts of India. The Western type of village system with easy access to fresh air all around and the abundant supply of water have contributed to the state's relatively high cleanliness in the villages and high standards of public health. In addition to the favorable environmental conditions, the long tradition of medical and health treatment systems comprising ayurveda, allopathy and homeopathy, and the modern hospitals with its well trained personnel established originally by the Christian institutions have contributed to create better health conditions in the state than in other states of India. The health sector in Kerala today is not only the top most among the states in India but also on a par with the developed countries (Manorama Year Book 2009).

Kerala is the home of the early Christians believed to have been converted by St. Thomas, the Apostle of Christ, in the first century A.D. The Christians represent $19.0 \%$ of the population (6.6 million) - the 
The Fertility Decline in India's Kerala State: A Unique Example of Below Replacement Fertility in a HIgh Fertility Country

highest number in any state in India, the Muslims $24.7 \%$, the Hindus $56.2 \%$, and $0.1 \%$ others (Sikhs, Budhists, Jains, etc.) (Manorama Year Book 2009: 206). It has a balanced religious composition, and is the only state in India with a sizeable number of the three religious groups. The high percentage of Christians and the work of Christian institutions have played a crucial role in the fields of education and health.

Another notable difference between Kerala and other States is its high educational attainment. Kerala has always been noted for higher literacy and educational level compared with the rest of India. In 1981 for example, while the literacy level for India was $44 \%$, Kerala's was $79 \%$, which increased to $65 \%$ and $91 \%$, in 2001 . For females the difference was greater with $73 \%$ for Kerala and 30\% for India in 1981 and $88 \%$ and $54 \%$ in 2001 . The improvement in literacy level was also greater in Kerala than in India. By 1991, Kerala became the first fully literate Indian State with literacy level of $90 \%$ and nearly $100 \%$ per cent enrolment at the primary school level.

There has also been a corresponding increase in the college level education as well. The contribution to education at all levels by the Christian institutions from early times and the policy of successive governments to promote school education were the prime factors for attaining high educational level in Kerala. Also, an important aspect of school attendance is that $49.1 \%$ of students attending are girls (Manorama Year Book 2009: 240). The high educational level of Kerala's population, especially of women as described, has great relevance in explaining the fertility decline.

Another notable feature is the political awareness and high participation of its people. The political consciousness of the people is very high with its impact on almost every aspect of life. The high educational level of the people, the large number of newspapers and their easy availability, and the party politics, especially the influence and grip of the communist party among the low strata and oppressed section of the society have been contributory factors for the unique political development. In 1957, the first democratically elected communist government in the world came into power in Kerala. This triggered a number of sweeping socio-economic legislations, especially land reform, affecting the distribution of income and services, and associated changes over the years. Many facets of Kerala's social, political and economic development since the 1950 s were influenced by the communist party and its governments. The socio-political changes have had their unintended outcomes in easily accepting family planning programs.

Low urbanization and the absence of the traditional rural-urban distinction are also distinguishing features of Kerala. In 1981, according to the census definition, the proportion of urban population was only 
$18.7 \%$ in Kerala compared with $23.7 \%$ in India as a whole. In 2001 the urban proportion was $25.6 \%$ in Kerala and $27.8 \%$ in India. Even today there is only one city (Greater Cochi) in the state with a population of little over one million. However, in reality it is perhaps a highly urbanized state. The villages are only administrative divisions, but most of them have many of the urban facilities that exist in urbanized areas. In fact, except for a few relatively undeveloped districts, much of the state can be considered urban from the point of view of living conditions and facilities.

Historically low mortality is another distinctive demographic feature of Kerala, which is related to the state's aforementioned geography and typical village system and better health conditions (for details, see the section on mortality).

All these developments and special features have had their influence on the demographic transition in Kerala. They provide the background information for explaining the rapid fertility decline in Kerala. The historical developments and unique features of Kerala with the socio-demographic processes and changes prompted the fertility decline. Similar views are expressed by Zachariah (1984) and Ratcliffe (1978) in their studies.

\section{A Glimpse of Kerala's Demographic Background}

Table 1 provides selected statistics on population trends and patterns in Kerala for the last century that validates the special demographic features stated earlier. Kerala, with a total population of 31.8 million in 2001, had an accelerated growth rate up to 1961-71 (except in 1911-21). Since then the growth rate declined with a steady downward trend. The declining mortality in the state contributed to the increasing growth rate in Kerala between 1921 and 1971. The decline in Kerala's growth rate since 1971 could be attributed to the rapid decline in fertility and the greater loss of population due to migration.

The population density of 165 persons per sq. kilometer at the beginning of the century rose to 819 by the end of the century, an increase of five times the level in 2001. The problems associated with this very high density of the population have been a factor for initiating the land reform in the 1960s and for the subsequent fertility decline. The data also reveal the state's historically increasing sex ratio in favor of women, i.e., more women than men.

The migration data show that the state which had been gaining population from migration until 1931 reversed the trend since then and started losing population (Table 1). The net out migration rate reached its 
The Fertility Decline in India's Kerala State: A Unique Example of Below Replacement Fertility in a HIgh Fertility Country

Table 1

Background Demographic Statistics for Kerala: 1901 - 2001

\begin{tabular}{cccccc}
\hline Year & $\begin{array}{c}\text { Population } \\
\text { (in 000s) }\end{array}$ & $\begin{array}{c}\text { Growth } \\
\text { Rate } \\
\text { (\%) }\end{array}$ & $\begin{array}{c}\text { Sex Ratio } \\
\text { F/M per } \\
\mathbf{1 , 0 0 0} \\
\text { population }\end{array}$ & $\begin{array}{c}\text { Population } \\
\text { Density }\end{array}$ & $\begin{array}{c}\text { Net } \\
\text { Migration } \\
\text { Rate ((\%) }\end{array}$ \\
\hline & & & & & \\
$\mathbf{1 9 0 1}$ & $6,396.30$ & -- & 1004 & 165 & -- \\
$\mathbf{1 9 1 1}$ & $7,147.70$ & 1.11 & 1008 & 184 & 0.03 \\
$\mathbf{1 9 2 1}$ & $7,802.10$ & 0.88 & 1011 & 201 & 0.04 \\
$\mathbf{1 9 3 1}$ & $9,507.10$ & 1.98 & 1022 & 245 & 0.12 \\
$\mathbf{1 9 4 1}$ & $11,031.50$ & 1.49 & 1027 & 284 & -0.01 \\
$\mathbf{1 9 5 1}$ & $13,549.10$ & 2.06 & 1028 & 349 & -0.11 \\
$\mathbf{1 9 6 1}$ & $16,903.70$ & 2.21 & 1022 & 435 & -0.20 \\
$\mathbf{1 9 7 1}$ & $21,347.40$ & 2.33 & 1016 & 549 & -0.16 \\
$\mathbf{1 9 8 1}$ & $25,453.70$ & 1.76 & 1032 & 655 & -0.22 \\
$\mathbf{1 9 9 1}$ & $29,098.50$ & 1.34 & 1036 & 749 & -0.31 \\
$\mathbf{2 0 0 1}$ & $31,838.60$ & 0.91 & 1058 & 819 & -0.27 \\
\hline
\end{tabular}

Source: Compiled from various censuses of India and other sources.

peak in 1981-1991. External migration has been to all parts of the world, but predominantly to the Gulf countries. It is reported that almost all families in Kerala are affected by migration to the Gulf region one way or another and its impact is felt in every aspect of life in the state. The outmigration over the years has been beneficial for Kerala in two principal ways. First, Kerala's economy and the out-migrant families benefit a great deal from the remittances of the migrants. Second, because of the migrants' exposure to people outside the state, especially to those in other developed countries, migration acts as an effective mechanism in diffusing new ideas of modernization and value systems in every sector of life. The inculcation of new ideas and lifestyle by the immigrants may have helped their families and the community at large in considering the benefits of voluntary and government-sponsored family planning programs. 


\section{Mortality Decline}

Kerala's demographic transition involved not only reduction in fertility but also a significant decline in mortality levels. Reduction in mortality generally precedes fertility decline. In explaining the demographic transition theory, it is hypothesized that fertility decline generally occurs in response to increases of infant and child survival. Although there has been an increase in child survival in Kerala due to decrease in infant mortality, its impact on fertility decline is not clear cut. As Dyson has put it, persistent and massive mortality decline has caused all sustained fertility decline since the late eighteenth century. Because sustained mortality decline leads to more surviving children and larger cohorts entering the working ages, it becomes a motivating factor of the behavioral change in controlling fertility. Thus, the remote causal force behind all fertility transition is mortality decline, which is true for the developing countries as well as for historical Europe (Dyson 2002: 392). Given the interrelationship between mortality and fertility declines, a brief discussion of mortality trends in Kerala compared with all-India is presented.

Kerala's death rate has always been lower than that of India. The crude death rate declined from about 25 per thousand population in the 1930s to below 7 in 1981 or earlier and remained stable between 6 and 7 since then. It was 6.6 in 2001 (Zachariah 1984; United Nations 2007). The India death rate during this period remained about 6 to 7 points above the Kerala rate. Much of the state's decline in death rate occurred before 1971 , i.e., before the fertility decline.

The largest reduction in mortality was in infant ages (Table 2). The infant mortality rate (IMR) per 1000 births in Kerala was also much lower than that of India. While the IMR in Kerala declined from 120 in 1951-60 to 56 in 1976, the rate in India remained fairly stable at 140 per thousand births in 1960-1975. The IMR in Kerala was 11 in 2001, which was even lower than in Eastern Europe (14), China (26), and Democratic Republic of Korea (50) (United Nations 2007).

A more reliable and widely used index of mortality is life expectancy at birth, estimated from census data for the period 1951-1961 to 1971-1971 and SRS data for the period 1970-1975 to 2000-2001 (Table 2) also confirms the low mortality level in Kerala. It shows two important differences between Kerala and India: (1) life expectancy in Kerala has been much higher than that in India; and (2) while in Kerala life expectancy has always been higher for females than males, in India it has been higher for males than for females until the recent years 
The Fertility Decline in India's Kerala State: A Unique Example of Below Replacement Fertility in a HIgh Fertility Country

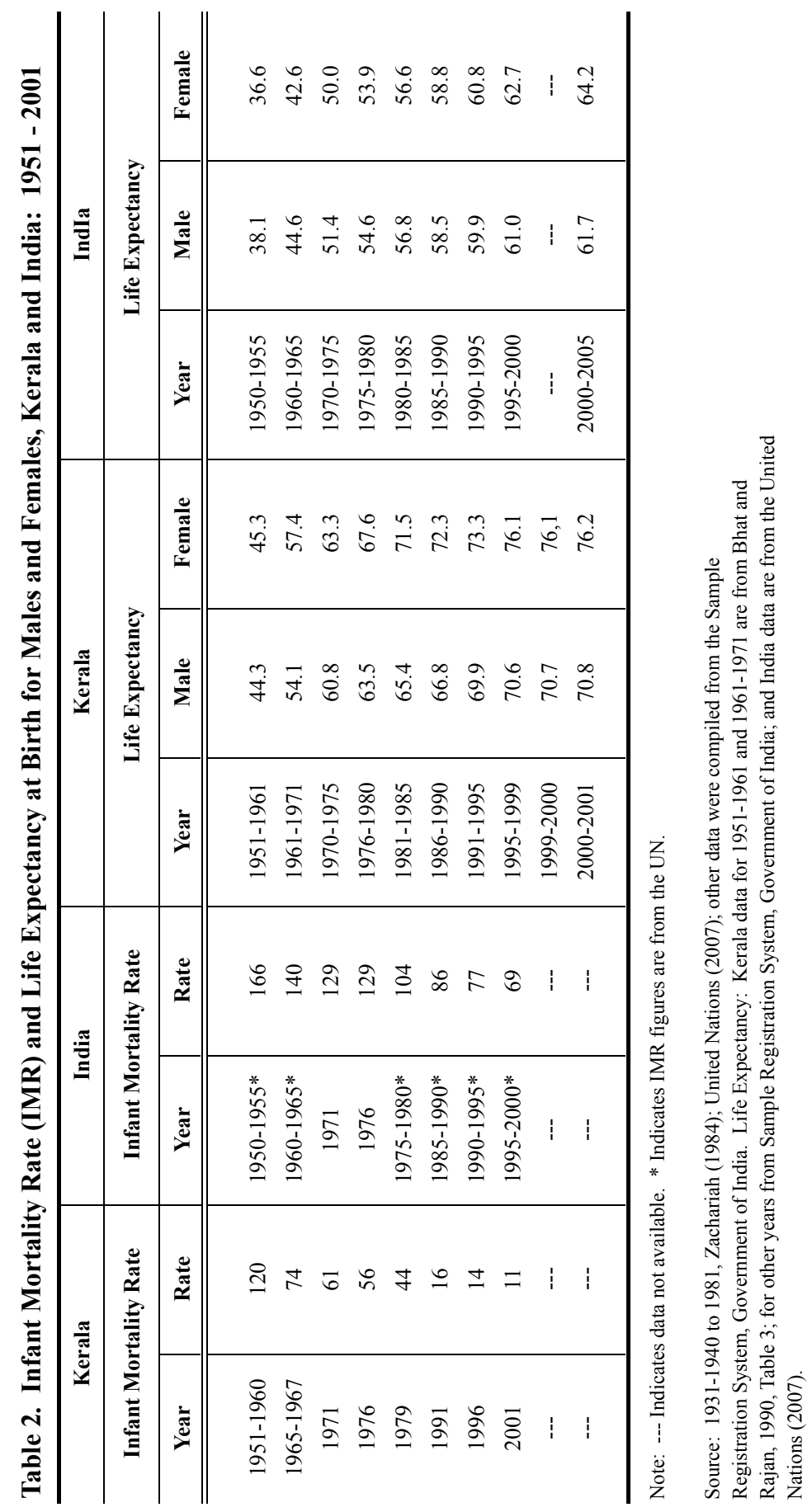


up to 1975-1980, as reported in the U.N. report (2007). The higher life expectancy for females in Kerala is consistent with its higher number of females than males.

The mortality measures for Kerala indicate that Kerala's mortality decline started long before the fertility declines were observed and continued its downward trend during the rapid fall in fertility. Low mortality is likely to have had some indirect influence in Kerala's fertility decline along with other factors; some of them are common determinants with their impact on both mortality and fertility decline. For example, the influence of women's education is an important common determinant with its impact on both mortality and fertility decline.

\section{Fertility Decline: Trends, Pattern and Differentials}

\section{Fertility Trends and Pattern}

Of the different sources of fertility estimates for Kerala and India, there are four principal sources: (i) official estimates; (ii) estimates based on Sample Registration System (SRS) data; (iii) independent estimates using census age distribution; (iv) estimates based on current fertility rates available form three National Family Health Surveys (NFHS): NFHS-1; NFHS-2; and NFHS-3. Although there are differences in the level of fertility shown by these estimates, particularly for the earlier years, they all show the rapid fall in fertility in Kerala since the 1960s. Table 3 presents the estimates of crude birth rates (CBR) from 1931 to 2005-06, and the total fertility rates (TFR) from 1951-61 to 2005-06.

The crude birth rate (CBR) started declining from about 40 per thousand populations before 1950, but the declining trend reached its momentum in the 1960s, and reached below 21, i.e., about half, by 1990 . Also, while there was little difference between the birth rate in Kerala and India during 1941-1950 period, the rates began to diverge markedly in the next decade onward. In 2005-06, the CBR in Kerala was 16.4, about 7 points lower than that of India (Table 3 ).

The total fertility rate (TFR) in Kerala was about 5.6 in 1951-1961 declined by $39 \%$ to 3.4 in $1971-1975$. This reflects a decline of around 2.2 children per woman in about 17 years. The TFR declined further to 2.1 (replacement level) in 1986-90, to 1.96 in 1989-99 and to 1.93 in 2005-06. In fact, the relative decline in TFR between 1971-1975 and 1986-1990 was steeper than in the previous period as the rate declined by $38 \%$ in about 15 years. With the fast decline in fertility in Kerala, the difference in the TFR between Kerala and India also increased from 0.7 children per woman in 1951-1961 to 1.4 children in 1971-1975. Because 
The Fertility Decline in India's Kerala State: A Unique Example of Below Replacement Fertility in a HIgh Fertility Country

Table 3

Crude Birth Rate and Total Fertility Rates

for Kerala and India: $1931-2006$

\begin{tabular}{cccccc}
\hline \multicolumn{3}{c}{ Crude Birth Rate } & & \multicolumn{2}{c}{ Total Fertility Rate } \\
\hline Year & Kerala & India & Year & Kerala & India \\
$1931-40$ & 40 & 45 & & & \\
$1941-50$ & 40 & 40 & & -- & - \\
$1951-60$ & 39 & 42 & $1951-61$ & 5.6 & -- \\
$1961-70$ & 37 & 41 & $1961-71$ & 5.0 & 6.3 \\
1971 & 32 & 37 & $1971-75$ & 3.4 & 4.8 \\
1976 & 26 & 34 & $1976-80$ & 3.1 & 4.5 \\
1981 & 26 & 33 & & -- & - \\
$1981-85$ & 24.6 & 33.6 & & 2.6 & 4.5 \\
$1986-90$ & 20.9 & 31.4 & & 2.1 & 4.0 \\
$1992-93$ & 19.6 & 28.7 & & 2.00 & 3.39 \\
$1998-99$ & 18.8 & 24.8 & & 1.96 & 2.68 \\
$2005-06$ & 16.4 & 23.1 & & 1.93 & 2.68 \\
& & & & & \\
\hline
\end{tabular}

Note: -- indicates figures not available.

Source: CBR: 1931-40 to 1981: Zachariah (1984), Table 3.3; 1981-85 to 19861990: Estimates from Sample Registration System; TFR: 1951 to 1971 are from Bhat and I. Rajan (1990), Table 9; 1971 to 1990: Estimates from Sample Registration System; 1992-1993 to 2005-2006: National Family Health Survey, NFHS-1, NFHS-2, and NFHS-3.

of the recent fertility decline in a number of states, the gap in TFR between Kerala and India has narrowed to 0.8 children in 2005-06 (Table $3)$.

The TFR does not show the age pattern of the fertility decline which is important for explaining the reason for the observed trend. This may be done by examining the age-specific fertility rates. For the early years of fertility decline, 1958-59, 1971, and 1976, age-specific rates are available only for the rural areas of Kerala (rural sample). These rates along with the rural age-specific rates for 1998-99, and 2005-06 derived from the National Family Health Survey (NFHS-2 and NFHS-3), respectively are used to examine the change in age pattern over the 195859 to 2005-06 period. They are provided in Table 4 and depicted in Figure 1, shedding further light on the decline. The table shows the agespecific fertility rates as well as the TFR associated with these rates. It also shows the percentage decline in age-specific rates between the periods, and the percentage contribution of each age group to the total fertility rate. 
As shown in Table 4, the TFR in Kerala's rural areas declined from 5.2 in $1958-59$ to 4.1 in 1971 and then to 3.4 in 1976, a decline of $35 \%$ in about 17 years. In absolute terms, this represented a decline of 1.8 children per woman in such a short period. Since then the TFR continued its decline at a slower pace to 2.1 in $1998-99$ and then to 2.0 in $2005-06$, a decline of $41 \%$ in about 30 years. With regard to the percentage contribution of different age groups to the total fertility rates in the first three periods, it can be seen that women in the age group 2529 contributed to the most, followed by the $20-24$ age group. In the recent years, however, women in the age group 20-24 contributed to the most followed by the 25-29 group. These two age groups together contributed to over $74 \%$ of the total fertility rates. Furthermore, the contribution of these two age groups increased over time. On the other hand, the contribution to the total fertility by women in the older age groups has been declining, with sharper decline in the 35 and over age groups. This is a pattern similar to what was observed among the low fertility countries in Western Europe in the 1990s (see United Nations 2000: Table 10).

The most interesting aspect of the trend in age-specific rates is that fertility declined in all ages (see Figure 1), with the largest decline in the 30 plus age groups during the entire period. Fertility in the youngest age group, $15-19$ declined by $45 \%$ in 17 years and another $12 \%$ in the next 5 years, with a total decline of $57 \%$ in 22 years. The rate in this age-group has remained fairly stable since 1976 . The steep decline in the 15-19 agegroup in the early period may be attributed largely to a decline in the proportion of this group that was married or an increase in female age at marriage between 1959 and 1976. The varying decline in the other age groups with greater decline in the older ages may be attributed to the effect of family planning or contraceptive use. The largest decline in the ages over 35 is a reflection of the increasing prevalence of sterilization among these women who opted not to have more children (see Zachariah 1984). The TFR remained fairly stable in the recent years which is reflected in the age pattern as well (Figure 1).

\section{Fertility Differentials and Decline by Socio-Economic Characteristics}

Are there significant socio- economic differentials in fertility in Kerala and to what extent has the fertility decline reflected by the women's socio-economic background? Table 5 presents estimates of TFR and the average number of children ever born (CEB) to women ages 45-49) from the 1981 Census and the more recent estimates of TFR from the three 
The Fertility Decline in India's Kerala State: A Unique Example of Below Replacement Fertility in a HIgh Fertility Country

Table 4

Age-specific Fertility Rates (per 1000 women) and Total Fertility Rates (TFR), Kerala: 1958-1959, 1971, 1976, 1998-1999 and 2005-2006 (Rural)

\begin{tabular}{|c|c|c|c|c|c|c|c|}
\hline Age Group & $\begin{array}{c}1958-1959 \\
\text { (NSS 14th } \\
\text { Round) }\end{array}$ & $\begin{array}{c}\text { Contribution } \\
\text { of each age } \\
\text { group to TFR }\end{array}$ & 1971 (SRS) & $\begin{array}{c}\text { Contribution } \\
\text { of each age } \\
\text { group to TFR }\end{array}$ & $\begin{array}{c}\text { Percent } \\
\text { Decline } \\
\text { 1958-1959 } \\
\text { to } 1971\end{array}$ & 1976 (SRS) & $\begin{array}{c}\text { Contribution } \\
\text { of each age } \\
\text { group to TFR }\end{array}$ \\
\hline 15-19 & 87.5 & 8.5 & 48.4 & 5.9 & 44.7 & 42.7 & 6.3 \\
\hline $20-24$ & 237.9 & 23.1 & 210.8 & 25.9 & 11.4 & 193.4 & 28.4 \\
\hline $25-29$ & 291.8 & 28.3 & 223.3 & 27.4 & 23.5 & 202.3 & 29.7 \\
\hline 30-34 & 205.1 & 19.9 & 173.2 & 21.3 & 15.5 & 137.1 & 20.1 \\
\hline 35-39 & 161.8 & 15.7 & 116.7 & 14.3 & 27.9 & 80.7 & 11.8 \\
\hline 40-44 & 46.7 & 4.5 & 42.8 & 5.2 & 8.4 & 25.3 & 3.7 \\
\hline 45-49 & 0 & 0 & 0 & 0 & 0 & 0 & 0 \\
\hline TFR* & 5. $15^{*}$ & 100.0 & 4. $07^{*}$ & 100.0 & 21.1 & $3.41^{*}$ & 100.0 \\
\hline Age Group & $\begin{array}{c}\text { Percent } \\
\text { Decline } \\
\text { 1971-1976 }\end{array}$ & $\begin{array}{c}\text { Percent } \\
\text { Decline } \\
\text { 1958-1959 } \\
\text { to } 1976\end{array}$ & $\begin{array}{l}\text { 1998-1999 } \\
\text { (NFHS-2) }\end{array}$ & $\begin{array}{c}\text { Contribution } \\
\text { of each age } \\
\text { group to TFR }\end{array}$ & $\begin{array}{l}2005-2006 \\
\text { (NFHS-3) }\end{array}$ & $\begin{array}{c}\text { Contribution } \\
\text { of each age } \\
\text { group to TFR }\end{array}$ & $\begin{array}{c}\text { Percent } \\
\text { decline } 1976 \\
\text { to 2005-2006 }\end{array}$ \\
\hline $15-19$ & 11.8 & 51.2 & 41.0 & 9.9 & 42.0 & 10.3 & 1.6 \\
\hline 20-24 & 8.3 & 18.7 & 179 & 43.2 & 162.0 & 398 & 16.2 \\
\hline 25-29 & 9.4 & 30.7 & 137.0 & 33.1 & 140.0 & 34.4 & 30.6 \\
\hline 30-34 & 20.8 & 33.1 & 39.0 & 9.4 & 50.0 & 12.3 & 63.5 \\
\hline 35-39 & 30.8 & 50.1 & 14.0 & 3.4 & 12.0 & 2.9 & 85.1 \\
\hline $40-44$ & 40.9 & 45.8 & 4.0 & 1.0 & 1.0 & 0.3 & 96.4 \\
\hline $45-49$ & 0 & 0 & 0 & 0 & 0 & 0 & 0 \\
\hline TFR* & 16.2 & 33.8 & $2.07 *$ & 100.0 & $2.03 *$ & 100.0 & 40.5 \\
\hline
\end{tabular}

Notes: 1 ) *Estimates are for rural Kerala, from the National Sample Survey (NSS) Report No.89; and National Family Health Survey (NFHS) Kerala, Table 11, 2008. 2. The age-specific rates are derived by dividing the number of births to women of a certain age by the number of women in that age group multiplied by 1000 .

Source: Zachariah (1984), Table 3.4; National Family Health Survey (NFHS) India and Kerala 1998-99 and 2005-06. 


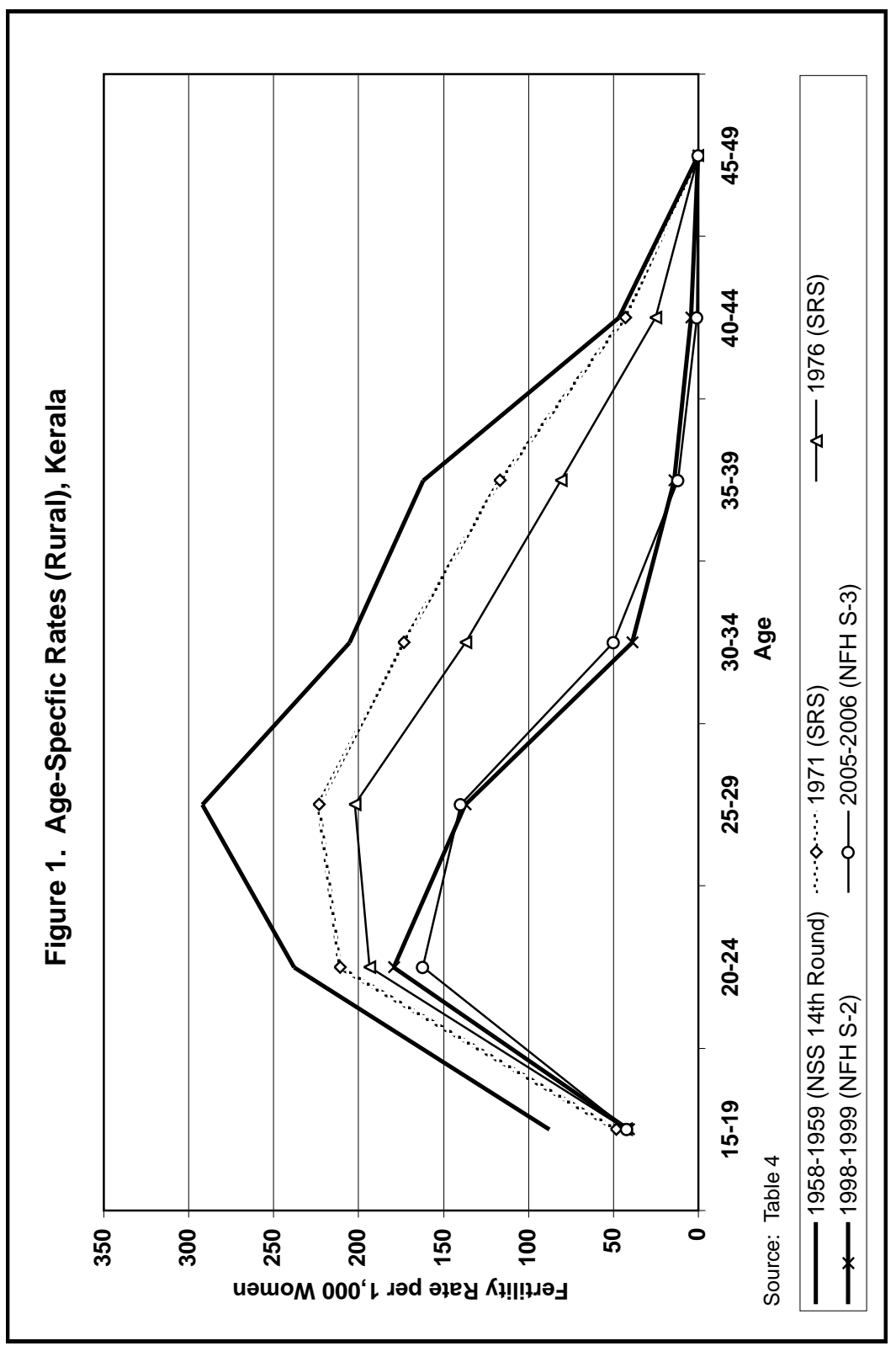

CSP 37.3-4: 563-600

576 
National Family History Surveys (NFHS), by women's socioeconomic characteristics. These data help gauge the fertility decline among various socio-economic groups over time. The rates on the mean number of children ever born to women ages 45-49 from the 1981 Census are cumulative rates of women born in the 1930s and reflect fertility in the past, whereas the TFRs represent fertility in the current years. The CEB rates, therefore, indicate the past fertility level and help discern the rapid decline in fertility since the 1960s. Assuming a mean age of childbearing of 28 years for the women 45-49 years of age, it can be inferred that the children ever-born reported by them were born in the early $1960 \mathrm{~s}$ (see Bhat and Rajan 1990: 1966).

Table 5 also shows that there are significant differences in fertility across the various groups. However, the differentials are more pronounced in the mean number of children ever born than by the TFRs. This indicates that the women 45-49 years of age had most of their births at an earlier age of the fertility transition. The average number of children born to all women ages $45-49$ is 4.7 to 5.1 , whereas the TFR is 2.1 to 2.5, a difference of about 2.6 children per woman. The pronounced differences between the two rates and the differentials by socio-economic characteristics substantiate that the rapid decline in fertility occurred since the 1960s and it was wide spread among the broad spectrum of the society.

The differentials are substantial in terms of education, occupation, and religion. Also, there are high urban and rural differentials, especially among the religious groups and the worker groups, with fertility levels lower among those living in urban areas. Further, the fertility rates by educational level in both the rural and urban areas confirm the inverse relationship between the levels of education and fertility. At the same time, as expected, there is very little difference in the TFRs between graduate women living in the urban areas and rural areas. This indicates the impact of education in influencing women opting for small family size, irrespective of the socio-economic differentials in fertility.

Historically, the census data on fertility differentials had shown that Hindus had the lowest fertility followed by Christians and Muslims (George 1959). Such a pattern is shown by the 1981 Census data and the more recent data from the National Family Health Surveys. The workergroup women had maintained a much lower fertility than the non-worker group. This is presumably an indication of the well-documented opportunity cost of child-bearing and the dampening effect on fertility when women combine both family and employment (see Chesnais 2000).

The latest data presented in Table 5 show that TFR has declined further with a more or less similar fertility pattern across the various groups as shown by the 1981 data. It is remarkable that fertility had 
The Fertility Decline in India's Kerala State: A Unique Example of Below Replacement Fertility in a HIgh Fertility Country

Table 5

TFR and Children ever Born (CEB) to Women Aged 45-49

1981 Census and TFR from NFHS 1992-93, 1998-99 and 2005-06 by Woman's Characteristics for Kerala

\begin{tabular}{|c|c|c|c|c|c|c|c|}
\hline \multirow{3}{*}{$\begin{array}{c}\text { Women's } \\
\text { Characteristics }\end{array}$} & \multicolumn{2}{|c|}{1981 Census } & \multicolumn{2}{|c|}{1981 Census } & \multicolumn{3}{|c|}{ Total Fertility Rate } \\
\hline & \multicolumn{2}{|c|}{ Total Fertility Rate } & \multicolumn{2}{|c|}{ CEB of Women 45-49 } & \multirow[b]{2}{*}{$1992-93$} & \multirow[b]{2}{*}{ 1998-99 } & \multirow[b]{2}{*}{ 2005-06 } \\
\hline & Rural & Urban & Rural & Urban & & & \\
\hline \multicolumn{8}{|l|}{ Educational Level } \\
\hline Illiterate & 2.95 & 2.47 & 5.16 & 4.98 & 2.31 & 2.22 & -- \\
\hline Middle & 2.23 & 1.92 & 4.52 & 4.25 & 1.95 & 2.14 & 2.05 \\
\hline Matric & 1.88 & 1.65 & 3.26 & 3.12 & 1.95 & 2.02 & 1.99 \\
\hline Graduate & 1.84 & 1.71 & 2.64 & 2.27 & -- & -- & -- \\
\hline \multicolumn{8}{|l|}{ Religion } \\
\hline Hindu & 2.26 & 1.80 & 4.79 & 4.41 & 1.66 & 1.64 & 1.53 \\
\hline Muslim & 3.72 & 3.08 & 5.90 & 5.73 & 2.97 & 2.46 & 2.46 \\
\hline Christian & 2.16 & 1.85 & 5.22 & 4.61 & 1.78 & 1.88 & $(2.11)$ \\
\hline \multicolumn{8}{|l|}{ Caste } \\
\hline Scheduled Caste & 2.41 & $* *$ & 4.99 & $* *$ & 1.37 & 1.52 & $(1.32)$ \\
\hline Scheduled Tribe & 3.02 & $* *$ & 5.16 & $* *$ & 1.29 & -- & -- \\
\hline Occupation & & & & & & & \\
\hline Main Worker & 1.96 & 1.34 & 4.61 & 3.71 & -- & -- & -- \\
\hline Non Worker & 2.75 & 2.19 & 5.27 & 4.96 & -- & -- & -- \\
\hline All Women & 2.52 & 2.07 & 5.07 & 4.69 & 2.00 & 1.96 & 1.93 \\
\hline Urban & NA & NA & NA & NA & 1.78 & 1.51 & 1.73 \\
\hline Rural & NA & NA & NA & NA & 2.09 & 2.07 & 2.03 \\
\hline
\end{tabular}

Notes** Included in rural area. -- Indicates data not available; ornot provided in the original table due to small sample; NA indicates not applicable. ( ) Based on 125-249 unweighted years of exposure for fertility rates and 25-49 unweighted cases for mean number of children ever born. A plausible rate in these cases would be at least the rates in 1998-1999.

Source: Bhat and Rajan (1990), Table 11; National Family Health Survey (NFHS-1, 1992-93; NFHS-2, 1998-99; and NFHS-3, 2005-06). 
fallen far below the replacement level in 1992-1993, with TFR varying between 1.29 to 2.31 for the women living in urban areas, among the Hindu, Christian, scheduled caste and scheduled tribe women, and among the women with middle school level education and higher. An interesting change that emerges from the recent data is that the differential impact of educational levels on fertility has been declining over time. As a result, there is very little difference in the fertility level among women with different educational levels. It is to be noted that only the Muslim and the illiterate women had fertility higher than the replacement level of 2.1 children per woman. The TFR of the Muslim women was not only the highest, but exceeded the replacement level by $41 \%$ in $1992-93$.

Since 1992-1993 the TFR has fallen to 1.93 in 2005-2006, a decline of only $3.5 \%$ in about 13 years. Similar decline occurred among women by socio-economic groups as well. It may be mentioned that the sample size of the 2005-06 survey for some of the characteristics reported is too small, affecting the accuracy of the results. The slight increase in fertility among women in the educational groups may be attributed to the sample size problem and to the lack of comparability in the classification of the four educational groups in the NFHS-3 data with the data for the earlier years.

While the fertility level declined for women in the socioeconomic groups, the fertility differentials also narrowed down over time among them. The recent data show that noticeable differentials persist only among the religious groups, especially between Muslims and Hindus/Christians, and by rural and urban residence. The TFR among Muslim women was $61 \%$ higher than that of the Hindus. Although the cause and effect of fertility decline and the narrowing of differentials cannot be easily determined, such convergence in the differences over time may be explained by the tendency among the groups with higher fertility levels to match the lower levels of fertility attained by the leading groups.

\section{Major Determinants of Fertility Decline}

Different approaches have been taken by demographers and other social scientists to explain the fertility transition in Kerala that occurred without the expected economic developments and urbanization. Some have tried to explain it in terms of the proximate variables that have a direct effect on fertility change, and others in terms of socio-economic and political factors affecting proximate variables. As indicated earlier, the analysis and discussion here will focus on two of the four proximate variables. 
The Fertility Decline in India's Kerala State: A Unique Example of Below Replacement Fertility in a HIgh Fertility Country

They are: (i) age at marriage; and (ii) family planning and use of contraceptive methods and associated variables, similar to the approach followed by ZachariaK(1984); Nag (1989); and Bhat and Rajan (1990).

\section{Marriage as a Determinant /Factor of Fertility Decline}

In Kerala, as in India as a whole, marriage can be considered a prerequisite for childbearing. Hence, the number of children a woman will have in her lifetime is strongly dependent on the age at which she gets married. The high concentration of fertility decline (over 51\%) in the youngest age group, 15-19 between 1958-1959 and 1976, as shown in Table 4, suggests the possibility that the changes in marriage patterns or age at marriage might have operated as a fertility regulating mechanism in Kerala. How much of the fertility decline since the 1960 s can be attributed to changes in age at marriage?

Although in some states in India marriage is not always immediately followed by cohabitation, in Kerala there is hardly any difference in age at marriage and age at cohabitation. In 1998-1999, for example, the median ages at first marriage and cohabitation with husband for women age 25-49 were 20.2 and 20.3, respectively (NFHS-1). The estimates on mean age at marriage of women (singulate mean age at marriage), calculated from census data on age-specific proportions single/never married for five year age groups 15-19 to 45-49, show that the mean age of marriage in Kerala has been the highest among the states in India since 1921, the first year for which comparable estimates are available. The mean age at marriage of women for Kerala has been higher than that for India by about 4 to 5 years (Table 6). The 1921 estimates for Kerala and India were 17.2 and 12.7 years respectively, which rose to 22.1 and 18.4 in 1981 . The estimates based on the NFHS show that the mean age at marriage for Kerala remained fairly stable since 1981. The rise in age at marriage or delay in entering a marital union indicates that an increasing number of women enter marital unions at later ages than previously with its associated impact in reducing fertility.

Further, as expected, there have been significant differentials in the average age at marriage of Kerala women of various socio-economic groups. The differences reported for the period 1961-1971 (Zachariah 1984) are the following: (i) illiterate women have lower age at marriage than those with at least ten years of schooling (a difference as high as 4.3 years); (ii) of the religious groups, Muslims have the lowest age at marriage (17 years) and Christians the highest age at marriage (20 years). 
The differences noted in the age at marriage have gone up further in the 1990s with its increased impact in recent years as indicated by the median age at cohabitation with the husband (the age by which half of the entire group of women begins to cohabit) in the National Family

Table 6

Singulate Mean Age at Marriage

Kerala and India: 1921-1992-93

\begin{tabular}{cccccccc}
\hline Area & $\mathbf{1 9 2 1}$ & $\mathbf{1 9 3 1}$ & $\mathbf{1 9 5 1}$ & $\mathbf{1 9 6 1}$ & $\mathbf{1 9 7 1}$ & $\mathbf{1 9 8 1}$ & $\begin{array}{c}\mathbf{1 9 9 2 -} \\
\mathbf{1 9 9 3}\end{array}$ \\
\hline Kerala & 17.2 & 17.6 & 19.9 & 20.2 & 21.3 & 22.1 & 22.1 \\
India & $12.7^{*}$ & $12.7 *$ & $15.6 *$ & 15.9 & 17.2 & 18.4 & 20.0 \\
\hline
\end{tabular}

Note: *12 states. Kerala estimates for 1921, 1931 and 1951 represent those of Former Travancore-Cochin.

Source: Collected from various sources and presented by Nag (1989), Table 8 up to 1951; the estimates for 1961 to $1992-1993$ are from NHFS-1 Report, Table 4.3 (estimated using the methods by Hajnal 1953, and Shryock and Siegel 1980).

Health Surveys $\square$ The NFHS-2 (1998-1999) data show that the difference in the median age at first cohabitation among women has gone up to 4.6 years between the illiterate and those completed high school and above (18.1 vs. 22.7 years). Thus, the median age at marriage increases with the level of education or the age at marriage is positively associated with years of schooling. The median age at marriage is also higher among women from households with a high standard of living, compared with women from households with a low or medium standard of living. The median age at cohabitation with the husband among women by religious group also increased with 23 years for Christians, 21 for Hindus and 18 for Muslims. Likewise, the median age at cohabitation increased to 22 years for urban and 20 for rural areas (NFHS-1, Kerala, 1998-1999 Table, 4.1).

Age at marriage may be determined by several factors such as legal limit (18 years for women and 21 for men), custom and tradition, desire to get married and economic factors. However, high literacy and educational level in Kerala is considered the principal determinant of the high age at marriage. In addition, the increasing dowry to be given by the 
The Fertility Decline in India's Kerala State: A Unique Example of Below Replacement Fertility in a HIgh Fertility Country

bride's family (despite that the practice was made illegal in 1961), and the deteriorating housing and employment situation in Kerala have been important factors for postponing marriage. The "marriage squeeze" - a demographic gap between the sexes (see Akers 1968) as a result of an imbalance in the number of men and women of marriageable age may also have had some effect in increasing the age at marriage.

A few studies have attempted to estimate the impact of increase in age at marriage on Kerala's fertility trends (see Zachariah (1984); Bhat and Rajan (1990). Of these, the most comprehensive analysis on the subject, based on data from a fertility survey in three districts in Kerala, is the study by Zachariah (1984); and Zachariah et al. (1992). Based on a multivariate regression analysis, which showed that most of the socioeconomic variables had an independent effect on age at marriage, and a decomposition procedure using (1) proportion of women married by age; (2) total marital fertility rates; and (3) total fertility rate (TFR), the study by Zachariah came up with an estimate of the contribution of the marriage factor or the increase in age at marriage on the fertility decline. According to this estimate, about $31 \%$ of the fertility decline in Kerala during 1965-1980 was due to the decline in the proportion of women married, mostly in the 15-19 and 20-24 year age groups (Zachariah 1984: 102-103). An earlier study by Krishnan (1976) has also indicated that the increase in age at marriage acted as a major factor in Kerala's fertility decline. On the other hand, the study by Bhat and Rajan (1990) using data from the census and SRS has come up with a lower estimate of $15 \%$ as the net effect of the marriage factor on the fertility decline between 1961 and 1981. However, for the present analysis, given the data sources and the estimation procedure used, Zachariah's estimate of about $30 \%$ is considered a reasonable figure of the impact of the marriage factor on the fertility decline in Kerala between 1965 and 1980.

\section{Family Planning and Use of Contraceptive Methods}

It has been shown that about $30 \%$ of the observed fertility decline between 1960 and 1980 was due to the impact of increase in age at marriage. The remaining $70 \%$ of the fertility decline during this period was attributed to a decline in marital fertility resulting from the practice of family planning or use of contraception.

There are three main sources of information on the practice of family methods. These are: (1) the official couple protection rate (CPR) derived form the statistics maintained by the Health and Family Welfare Centers; (2) the periodic surveys conducted in Kerala that provide information on the couples using family planning methods (for details, 
see Bhat and Rajan 1990); and (3) the three recent National and Family Health Surveys (NFHS-1, 1992-93; NFHS-2 1998-99; and NFHS-3 2005-06). These together provide a good account of family planning and fertility control in Kerala since the 1950s.

Table 7 presents the couple protection rate (percentage of couples effectively protected from pregnancy) for Kerala, 1981 to 1997 . It shows that since 1985, the couple protection rates (CPR) for the four main contraceptive methods (sterilization, IUD, conventional method and oral pills) varied between $40.0 \%$ in 1985 to $55.6 \%$ in 1991 . It also shows that in Kerala, sterilization was the principal method used for fertility control, with a rate of $40 \%$ or more from 1985 onward. A review of the CPR estimates has concluded that the Kerala estimates were an underestimate and should be adjusted upward by at least 6\% (Bhat, Rajan and Navaneetham 1989).

Table 7 also presents the percentage of contraceptive use among currently married women, 1992-93 to 2005-06. They show the continuation of the high contraceptive prevalence rate in Kerala in the most recent years with $69 \%$ in 2005-06, up from 64\% in NFHS-2 and $63 \%$ in NFHS-1. As experienced in the peak period of the family planning drive in the 1970 s, sterilization continues to be the main method used. It accounted for $76 \%$ of all methods used in NFHS-2, but has gone down to $71 \%$ in $2005-06$. This drop may be attributed to the decline in male sterilization that has more than halved since NFHS-2. Also, in the $1990 \mathrm{~s}$, the modern methods used included condom and oral pill (NFHS 2005-06: 8).

The NFHS results also provide the background characteristics of the contraceptive users (Table 8). The following are the notable findings: (1) Contraceptive use of any method increases sharply with age from $20 \%$ among women $15-19$ years of age to $81 \%$ among women age $40-49$. (2) The rate is almost the same in both the rural and urban areas that is consistent with the state's typical village set-up, low urbanization and the absence of the traditional rural urban distinction. (3) Contraceptive practice is higher among women with less than five years of schooling and no education than those with higher educational level. This is different from the pattern cited in demographic literature with regard to the association between rise in education and fertility decline (see Diamond et al. 1999). A similar pattern has been reported in a paper by Bhat (2002) where it is shown through a decomposition of change in fertility differentials by education in three periods - 41981-1991, 1970 1993, and 1993-99 - that the recent fertility decline in India is due to its decline among illiterate women. The deviant pattern of increased use of contraception among the illiterate women in the later phase of the fertility decline may be attributable to the diffusion idea of the benefit of fewer 
The Fertility Decline in India's Kerala State: A Unique Example of Below Replacement Fertility in a HIgh Fertility Country

Table 7

Couple Protection Rates (CPR) 1981-1997 and Current Use of Contraceptive Methods 1992-1993 to 2005-2006 for Kerala

\begin{tabular}{|c|c|c|c|c|c|c|c|}
\hline \multirow{2}{*}{ Year } & \multicolumn{7}{|c|}{ Effectively Protected/Use (\%) } \\
\hline & Sterilization & IUD & \multicolumn{2}{|c|}{ Conventional Method } & Oral Pills & \multicolumn{2}{|c|}{ All Methods } \\
\hline 1981 & 28.2 & 0.9 & \multicolumn{2}{|c|}{0.3} & 0.0 & \multicolumn{2}{|c|}{29.4} \\
\hline 1985 & 36.8 & 1.8 & \multicolumn{2}{|c|}{1.4} & 0.0 & \multicolumn{2}{|c|}{40.0} \\
\hline 1990 & 43.3 & 4.8 & \multicolumn{2}{|c|}{3.4} & 1.0 & \multicolumn{2}{|c|}{52.5} \\
\hline 1991 & 45.8 & 5.2 & \multicolumn{2}{|c|}{3.6} & 1.0 & \multicolumn{2}{|c|}{55.6} \\
\hline 1996 & 41.3 & 3.9 & \multicolumn{2}{|c|}{2.8} & 0.8 & \multicolumn{2}{|c|}{48.8} \\
\hline 1997 & 40.0 & 3.7 & \multicolumn{2}{|c|}{2.4} & 0.7 & \multicolumn{2}{|c|}{46.8} \\
\hline \multirow{2}{*}{ Year } & \multicolumn{7}{|c|}{ Current Use of Contraceptive Methods by Currently Married Women (\%) } \\
\hline & Sterilization & IUD & Oral Pills & Condom & $\begin{array}{l}\text { Conventional } \\
\text { Method }\end{array}$ & All Methods & Not Using \\
\hline $\begin{array}{l}\text { NFHS-1 } \\
1992-93\end{array}$ & 48.3 & 2.7 & 0.5 & 2.9 & -- & 63.3 & 36.7 \\
\hline $\begin{array}{l}\text { NFHS-2 } \\
1998-99\end{array}$ & 51.0 & 1.6 & 0.4 & 3.1 & -- & 63.7 & 36.3 \\
\hline $\begin{array}{l}\text { NFHS-3 } \\
2005-06\end{array}$ & 49.7 & 2.3 & 0.4 & 5.5 & 10.7 & 68.6 & 31.4 \\
\hline
\end{tabular}

Notes: CPR is the estimate of couples effectively protected from pregnancy by using different methods of family planning. It is estimated by including all those who accepted the methods in the past and in the current year leaving out those who have dropped out because of mortality or widowhood and attrition due to ageing or leaving out those who have dropped out because of
discontinuation of the method (see Kapoor 1989).

Source: CPR: Compiled from various Family Welfare Programme Yearbooks, Ministry of Health and Family Welfare, New Delhi; and current use of contraceptive methods (\%), National Family Health Survey, 1998-99; 1996-98; and 2005-06. 
Table 8

Percent Distribution of Currently Married Women

by Contraceptive Method Used

and Selected Background Characteristics, Kerala: NFHS-3

\begin{tabular}{|c|c|c|c|c|}
\hline Variable & Any Method & Sterilized Female & $\begin{array}{c}\text { Any Traditional } \\
\text { Method }\end{array}$ & $\begin{array}{c}\text { Not Currently } \\
\text { Using }\end{array}$ \\
\hline \multicolumn{5}{|l|}{ Age Group } \\
\hline $15-19$ & 19.7 & 0.0 & 7.1 & 80.3 \\
\hline $25-29$ & 55.4 & 29.8 & 12.8 & 44.6 \\
\hline $40-49$ & 80.7 & 66.3 & 8.7 & 19.3 \\
\hline \multicolumn{5}{|l|}{ Residence } \\
\hline Urban & 68.9 & 45.6 & 10.4 & 31.1 \\
\hline Rural & 68.5 & 50.3 & 10.8 & 31.5 \\
\hline \multicolumn{5}{|c|}{ Education (Schooling) } \\
\hline No education & 72.6 & 65.5 & 4.4 & 27.4 \\
\hline$<5$ years & 77.2 & 69.8 & 3.1 & 22.8 \\
\hline 5-9 years & 69.7 & 55.2 & 8.7 & 30.3 \\
\hline$>10$ years & 65.5 & 36.6 & 14.8 & 34.5 \\
\hline \multicolumn{5}{|l|}{ Religion } \\
\hline Hindu & 74.4 & 54.7 & 9.3 & 25.6 \\
\hline Muslim & 54,6 & 38.9 & 9.3 & 45.4 \\
\hline Christian & 75.2 & 45.9 & 18.9 & 24.8 \\
\hline Scheduled & 76.9 & 64.2 & 7.1 & 23.1 \\
\hline Other & 69.2 & 47.6 & 11.8 & 30.8 \\
\hline Total & 68.6 & 48.7 & 10.7 & 31.4 \\
\hline
\end{tabular}

Source: National Family Health Survey (NFHS-3) 2005-2006, Table 21. 
The Fertility Decline in India's Kerala State: A Unique Example of Below Replacement Fertility in a HIgh Fertility Country

children and giving them good education for a better future - a choice of quality over quantity in family size. (4) Muslim women are less likely to use any contraceptive method (55\%) than are Christian and Hindu women $(74 \%$ to $75 \%)$. This factor explains the continued high fertility level among Muslim women. (5) As noted for the illiterate women, contraceptive use is higher among women belonging to the scheduled caste. (6) In all categories of women, sterilization continues to be the predominant method used. And (7) the use of traditional methods is more prevalent among women in the age group 25-29, among women with a higher educational level, and among Christians.

Several surveys have been conducted in the early period of fertility decline in Kerala during 1958-59 to 1980 to collect data on knowledge and practice of contraception. The results of these surveys are reported to be of variable quality. The data on knowledge and practice of family planning methods summarized from ten surveys by Bhat and Rajan (1990) show that the knowledge of the contraceptive methods and their use rose rapidly during the 1960s. Of these, a survey by Operations Research Group in 1980 reported that $62 \%$ of married women 15-49 were using contraceptive methods. This figure was $10 \%$ higher than that of the estimate based on the World Bank survey of three districts in Kerala for the same year. The World Bank survey also showed that $89 \%$ of the married women 15-49 in rural areas had knowledge of various contraceptive methods.

A comprehensive account on family planning since 1956 is provided by the aforesaid study by Zachariah (1984) based on the results of the World Bank Survey. It is reported that Kerala has had the most successful family planning program in India with its great impact on the rapid fertility decline. The program started in 1955 with 11 clinics, had four distinct phases of development: 1955-1964; 1964-1970; 1970-1973; and 1973 onward. Some of the highlights of this program were the opening of a large number of family planning clinics throughout the state; the establishment of numerous family planning centers (one per 1000 population in rural areas); the innovative mass sterilization camps with the new sterilization technique not requiring hospitalization; and the appealing incentive program of either in kind or cash to the clients, promoters and doctors.

A "cafeteria" approach was followed by the state for the implementation of the family planning program and a variety of methods were offered to the public for their choice with proper consultations. As noted earlier, of the various methods offered, sterilization was the most effective and popular program.

The implementation of the well orchestrated official family planning program in Kerala with a variety of contraceptive choices and 
incentives played an important role in reducing fertility level. The vasectomy camps and other vigorous family planning actions by the Kerala Government are widely quoted as examples for effective methods in a society with low economic development.

A paper by Zachariah and Kurup (1984) using the 1980 fertility survey data provide the quantitative effect of family planning on fertility decline. This study provides the marital fertility level and the number of births averted by acceptance of various family planning methods, including sterilization, offered by the government program. A comparison of the rates for the five-year periods, 1965-70 to 1975-80 shows that the births averted and the total marital fertility rate (TMFR) are negatively related. The rank correlation analysis performed shows that the correlation coefficient between births averted in a district in a given period and its corresponding fertility level is -0.7 , which is statistically significant. Another interesting finding is that the expected effect of sterilization, the most widely used method, was a decline of 0.92 of a child per married woman.

It is also reported that almost all of the reduction in the birth rate in the state, which is not attributed to an increase in age at marriage, was accounted by family planning acceptance through the government program. The estimates of total births averted in the state from the $1960 \mathrm{~s}$ were 1,736,000 births by 1978, and 2,238,000 births by 1980 (Zachariah 1984).

\section{Socio-Economic Factors Affecting the Proximate Variables Considered}

Bhat and Rajan (1990) discusses two dominant theoretical approaches on fertility decline within marriage and the extent of their application to Kerala's fertility transition. The first is based on the effect of structural change which leads to the consideration of economic costs and benefits that childbearing entails to parents coupled with pensions and support at old age. The second is the diffusion approach in which fertility declines basically through the spread of birth control methods and programs. Such an explanation has been emerged in the case of fertility transition in Europe and in some developing countries based on World Fertility Survey data (see Cleland and Wilson 1987). After a review of the two approaches in the Kerala context, Bhat and Rajan have taken the view that the fertility transition in Kerala is more consistent with the diffusion perspective. They have also reviewed some other widely quoted studies on the decline in fertility (Ratcliffe 1978; Mencher 1980; Basu 1986; 
The Fertility Decline in India's Kerala State: A Unique Example of Below Replacement Fertility in a HIgh Fertility Country

Nair 1986; and Zachariah 1984) and concluded that the fertility transition occurred in Kerala without significant structural change in the economy.

The analysis of the data on demographic transition in Kerala and reviews of the existing studies on the subject suggest that it is difficult to come up with a single all-embracing theoretical explanation of the fertility decline that occurred there since the 1960s. The study by Zachariah (1984) which was primarily focused on addressing the issue, is one of the best sources for providing credible explanations for the rapid fertility decline. There are three interdependent factors or group of factors that triggered the decline. First, the significant impact of increase in age at marriage or postponement of marriage that accounted for about $30 \%$ of the decline. Second, the government sponsored family program, providing congenial and effective means for reducing marital fertility or achieving desired smaller family size among couples of all socioeconomic and cultural groups. Third, the unique Kerala characteristics that existed and the series of socio-economic changes that took place around the period of the fertility transition.

A few selected underlying socio-economic factors are chosen to explain the dynamics of the two proximate variables discussed earlier. They are (i) literacy and education; (ii) child survival; (iii) land reform; (iv) economic condition; and (v) women's status. These factors have had varying degrees of influence in motivating the couples to reduce fertility by resorting to suitable methods of fertility control.

\section{Literacy and Education}

The very high level of literacy and education in Kerala, especially among the females, compared with the national level has already been described. Studies on fertility have documented that mass education is an important determinant in fertility decline through its effect on the use of contraception and female age at marriage (Caldwell 1980; Nag 1989).

What is the process by which education acts as a contributing factor in reducing fertility? The effect of education on fertility can be considered a two-way process. One is its direct impact on acquiring the knowledge of family planning methods and getting motivated to accept and practice suitable family methods to reduce the family size. The regression analysis on factors related to fertility by Zachariah (1984) shows that the years of schooling of women had an independent effect on fertility. This suggests that better educated women accepted and used family planning more easily and efficiently than less educated women. Another related aspect is the diffusion impact of literacy and educational levels, and more importantly of educated women. The more literate and 
educated women are generally the first to get motivated to acquire information on family planning and start using birth control methods. They are likely to be the first to experience the effect of reduction in infant and child mortality and the increase in child survival and realize the value of reduced family size. They also help spread the beneficial message of limiting family size.

The other element of the process is the indirect effect of education through its cost benefit analysis in motivating people to adopt family planning. This aspect of education with its impact on both the parents and the children has affected the change in attitude towards smaller family size. A corollary to the effect of high literacy and educational level is the spread of mass communication through newspapers, radio, and TV.

Given the possibility that fertility levels have significant impact on the education of children, a simple macro-level analysis of the relationship between female education and fertility may lead to misleading findings (see Dyson 2002). In analyzing the effect of education on fertility, it is necessary to separate and quantify (1) the effect of mother's educational level on her fertility and (2) the effect of mother's fertility on the children's schooling. It seems that during the early phase of the fertility transition, the first effect dominates and the second effect is applicable in the later phase of the transition when contraceptive prevalence rate among illiterate and less educated women exceeds that of the more educated women (see Table 8).

\section{Child Survival}

Mortality decline has acted as a causal factor behind fertility transitions. As a result of the rapid decline in infant and child mortality in Kerala, the survival of infants and children improved significantly during the 1970s and 1980s (see Table 2). Over 90\% of those born today survive to adulthood. Can the decline in fertility be interpreted as an adaptive response to increased chances of infant and child survival? As Ratcliffe (1978) indicated, the answer to the question is not clear-cut. He also made a point that mortality declines influence fertility only marginally. However, the decline in infant and child mortality has had a direct and indirect effect on desired family size (Zachariah and Kurup 1984). The increasing survival probability of children must have been a contributory factor for the widespread acceptance of sterilization as an effective method for limiting family size. 
The Fertility Decline in India's Kerala State: A Unique Example of Below Replacement Fertility in a HIgh Fertility Country

\section{Land Reform}

The study by Ratcliffe (1978) gives much weight to the equitable distribution of wealth and income, brought about by the effect of social and economic reforms by successive governments, on fertility decline. His assertion is based on the assumption that an increase in wealth would automatically lead to a reduction in fertility. This is not true. If the rise in income is not accompanied by an increase in the opportunity costs of childbearing, fertility may increase. In a multivariate analysis of the Kerala fertility survey data, Zachariah (1984) has found that the amount of land owned was positively related with the number of children ever born, and inversely related to the use of contraception.

It is therefore likely that the land reform and the redistributive policies of the communist dominated governments of Kerala have changed the attitude of people toward landed property as a source of economic security. This prompted them to start investing in their children's education. Hence, it is likely that they switched from quantity over quality of children, which contributed to the very high contraceptive prevalence among them as seen earlier (see Table 8).

\section{Economic Conditions}

The per capita income, based on the official statistics, had been lower in Kerala compared with other states. For example, the per capita income in Rupees reported was 594 for 1971-1991; 1,421 for 1980-81; and 2,076 for 1984-1985 (Nag 1989: Table 5). The data on household and expenditure collected in the National Sample Survey also support the poor economic condition of Kerala. For example, in 1965-66, 70\% of the population was below the poverty line. Based on these official economic statistics, Kerala had been rated as one of the poorest in India. The relatively poor economic conditions as reported have prompted some analysts to argue that fertility decline was due to birth control on the part of poor wage earners (see Basu 1986; Mencher 1980). However, there is no evidence of prevailing high poverty in Kerala, and the poverty-based explanation of fertility decline is therefore on shaky grounds.

First, the statistics on per capita income for the years reported above is questionable due to the non-reporting of agricultural income, which is quite high in Kerala due to the variety of cash crops. Second, much of the remittances from Keralites living outside the state were unaccounted. In 2005-2006 the per capita income in Kerala was Rs.30,668 (Manorama Year Book 2009), which is 15 times higher than the average income reported for 1984-1985. It is also higher than the 
Indian average, and comes fairly close to the per capita income in the rich states of India. Although the per capita income in 1984-1985 was likely to be lower than the figure for 2005-2006, the large difference between the two income figures indicates that the former figure was a gross underestimate. Hence, the poverty induced theory of explaining fertility is not based on solid facts. A plausible explanation is that the increasing aspiration of parents for children's education and health, rather than poverty, has altered the cost benefit ratio for children in Kerala (see Zachariah and Kurup 1984).

\section{Women's Status}

It is argued that in general, there is a negative association between status of women and fertility. Status in this context is referred to as the position women hold in the family and in the social structure of a society (see Dyson and Moore 1983). To what extent the distinctive women's autonomy and societal position in Kerala has aided the fertility decline? One of the studies that deals with this subject is by Nair (1986) who has highlighted the greater autonomy of Kerala women.

The women's higher status is attributed to the matrilineal family position that has been followed until recently by a substantial proportion of the population, specifically the Nair community at large. Under the matrilineal system, the girls do not change residence upon marriage, and the property inheritance is along the female line. It is reported that in 1971 about $17 \%$ of the households were headed by a female, and in onefifth of the female headed households, a married daughter was also living there (See Bhat and Rajan 1990). This system, although weakened, together with high literacy and educational level of the women, has contributed to the empowerment of women in Kerala with an independent outlook, authority and influence within the family and in the society. It also had its effect in enhancing women's social mobility.

In addition to the high status Kerala women have been holding in their own families, they have been playing an active role in all fields with increasing education and opportunities. The women's autonomy and position in Kerala have had its influence in the fast adoption of contraceptive methods and for increasing the age at marriage for women. 
The Fertility Decline in India's Kerala State: A Unique Example of Below Replacement Fertility in a HIgh Fertility Country

\section{Comparison of Kerala's Fertility Transition with Selected Countries of Similar Experiences in the Region}

The countries selected for the comparison are: China, Hong Kong, the Republic of Korea, Singapore, Thailand and Sri Lanka which have experienced similar demographic transition and reached below replacement fertility level. In comparing the recent demographic transition with the rapid fertility decline in these six countries with Kerala, it should be noted that Kerala is only a small state of India with its constraints, and not an independent county. Consequently, unlike the six countries, Kerala's family planning programs have been a part of the national policy and it has to function within the state jurisdiction, powers and resources. Notwithstanding these fundamental differences, the object of this comparison is to give a brief overview of the similarities and differences in the demographic trends, the policies and programs followed in lowering the fertility levels and the underlying socio-economic and political factors that contributed to it.

In all these countries fertility was high in the 1950s and the 1960s. As can be seen from Table 9, in late 1960 fertility declined in Singapore, Hong Kong, Republic of Korea and Sri Lanka. Mortality, especially infant mortality, which was already low, also declined rapidly along with fertility. It is of special interest to compare Singapore and Hong Kong, both are urbanized areas or city nations. It has been reported that Singapore introduced strong family planning program dominated by government initiative and direction. In Hong Kong, on the other hand, the family planning program was led by non-government organizations (Jiang 2000). In both countries, fertility levels dropped quickly and reached below replacement level within 15 to 20 years and have been at that level since then. In Singapore, the decline was faster, reaching the low level in about 10 years mainly because of the great push by the Government, concerned with the extremely high population density. Unlike Kerala, both these countries were two of the four so-called "little economic tigers in Asia" (the other two countries are Republic of Korea and Taiwan). The fast economic development there triggered the demand for family planning services.

It is reported that a baby boom period appeared in China, Republic of Korea and Thailand soon after the Second World War. This resulted in high fertility and population growth rates which seemed to have shocked the governments of these countries (Jiang 2000). In Thailand a very high TFR of 6.4 was reported in 1960-1965. Since the early 1970s these governments therefore adopted an anti-natalist policy and implemented family planning programs. In the Republic of Korea, fertility decreased 
Table 9

Total Population, Total Fertility Rate and Infant Mortality Rate,

China, Hong Kong, Republic of Korea, Singapore, Sri Lanka, Thailand, and Kerala: 1960-2005

\begin{tabular}{|c|c|c|c|c|c|c|c|}
\hline TFR and IMR & China & Hong Kong & $\begin{array}{l}\text { Republic } \\
\text { of Korea }\end{array}$ & Singapore & Sri Lanka & Kerala & Thailand \\
\hline $\begin{array}{c}\text { Total Population } \\
2001 \text { (in milliona) } \\
\text { TFR }\end{array}$ & $1,269,962$ & 6,662 & 46,780 & 4,017 & 18,714 & 31,839 & 61,438 \\
\hline 1960-1965 & 5.62 & 5.31 & 5.63 & 4.93 & 5.12 & $5.0(1961-71)$ & 6.40 \\
\hline $1970-1975$ & 4.86 & 2.89 & 4.28 & 2.62 & 4.12 & $3.4(1971-75)$ & 4.97 \\
\hline 1980-1985 & 2.55 & 1.80 & 2.23 & 1.69 & 3.16 & $2.6(1981-85)$ & 3.05 \\
\hline $1990-1995$ & 1.92 & 1.29 & 1.70 & 1.76 & 2.48 & $2.0(1992-93)$ & 2.10 \\
\hline $1995-2000$ & 1.78 & 1.08 & 1.51 & 1.57 & 2.22 & $1.96(1998-99)$ & 1.95 \\
\hline $\begin{array}{c}\text { 2000-2005 } \\
\text { IMR }\end{array}$ & 1.70 & 0.94 & 1.24 & 1.35 & 2.02 & $1.93(2005-06)$ & 1.93 \\
\hline 1960-1965 & 121 & 33 & 70 & 30 & 63 & 74 (1965-67) & 84 \\
\hline $1970-1975$ & 61 & 17 & 38 & 19 & 50 & $57(1975)$ & 66 \\
\hline 1980-1985 & 38 & 10 & 23 & 8 & 29 & - & 47 \\
\hline 1990-1995 & 30 & 5 & 14 & 6 & 17 & 15 (1995) & 29 \\
\hline $1995-2000$ & 28 & 4 & 8 & 4 & 15 & 14 (1996) & 23 \\
\hline 2000-2005 & 26 & 4 & 5 & 3 & 12 & $11(2001)$ & 20 \\
\hline
\end{tabular}

Notes: The parenthesis represents the actual year; - indicates the item is not available.

Source: For the six countries, United Nations 2007; and for Kerala, Tables 1, 2, and 3. 
The Fertility Decline in India's Kerala State: A Unique Example of Below Replacement Fertility in a HIgh Fertility Country

to below replacement level in the1980s. China and Thailand reached this level about 10 years later. Concerned with the fast growth of population in Thailand in the 1960s, the Government formally announced a voluntary family planning program in 1970 that took momentum since then. The contraceptive prevalence rate of married women age 15-44 increased from $15 \%$ in $1969-1970$ to $65 \%$ in 1984 , and further increased to $74 \%$ in the 1990 s (Jiang 2000). It appears that the non-governmental organizations made a big dent to the success of the family planning program in Thailand.

China experienced a similar transition process as in Thailand. Since large family had been the preference traditionally, contraceptive methods were used only for health reasons in China in the 1950s. However, in 1964 faced with the serious employment and food problems and the population pressure, the Government established the Family Planning Council under the State Council of China. It started to implement a family program first in large cities and selected rural areas. The "Cultural Revolution" interrupted the family planning program with its consequences and hard realities of the population problem. With the population reaching around 800 million, curbing population growth became an urgent target and the Government returned to family planning program in 1973. Because of the interruption in its family planning program, it took more time for the TFR in China to reach the replacement level. A policy of well-spaced and fewer births were introduced. Also, static population and zero growth targets were set up, and late marriages, late births and the idea of having fewer and healthier babies, only one child per couple, was encouraged. The one child per family was introduced in 1979. The family planning program introduced was very massive with about 400,000 family planning workers in 1996 and over 50 million volunteers (mostly retired people) (Jiang 2000).

Correspondingly, in China and in the four South-East Asian countries with little similarities with Kerala, an effective family planning program was the principal reason for fertility decline. In Thailand and Hong Kong, the program was mainly implemented by the nongovernmental organizations. In the three other countries the program was run directly by their Governments. Both programs were effective. But other factors also, directly and indirectly, affected the fertility transition. These include education, socio-economic development, and improvement in health care system and change in the life style of the people. The fertility decline achieved in these five countries by an effective family program has some parallel to the way fertility decline occurred in Kerala. However, the socio-economic and political conditions and ethnic composition of the population in these countries are much different from Kerala. The similarities may be found primarily in literacy and education, 
mortality levels and the means used to reduce fertility levels. These countries have had much higher per capita income, higher proportion of the labor force in non-agricultural occupations, higher level of urbanization, higher nutrition levels and standards of living, and higher expenditures on family planning programs than Kerala. It is also likely to have differences in other indicators of social and economic change. The political setup in these countries, especially in China, has also been different from Kerala.

The only country shown in Table 9 which has more similarities with Kerala in terms of socio-economic development and demographic perspectives is Sri Lanka. However, the fertility level in Kerala declined much faster and to a lower level than in Sri Lanka (see Table 9). This may be attributed to the difference in the family planning programs and their implementation in Sri Lanka and Kerala. One main factor that contributed to this difference appears to be the lack of thrust in promoting sterilization in Sri Lanka's program (see Zachariah 1984). It requires a more thorough investigation and analysis with comparable and more detailed socio-economic and family planning program data to come up with the factors responsible for Sri Lanka's slower fertility decline than in Kerala.

\section{Concluding Comments}

Kerala experienced a sharp fall in fertility in the 1960s preceded by a long-term decline in mortality level. It occurred without the required conditions associated with the classical demographic transition. If Kerala were to follow the conditions for rapid economic development and urbanization as essential prerequisites, then it would not have experienced such a rapid decline in fertility and the consequent replacement level in less than three decades. Kerala's experience is thus viewed as a paradox and a unique example to demonstrate that fertility can be reduced without significant economic development. However, its enviable socio-economic developments with high level of literacy and education achieved as a state within in India, acted as the most favorable background to carry out its aggressive family program successfully.

From a policy perspective, how much help would the Kerala experience be in shaping programs in other states to reduce their respective fertility levels? The answer depends on consideration of the current demographic situation in several states since Kerala's fertility transition. The NFHS-3 data show that already in three states (Andhra Pradesh, Goa, and Tamil Nadu) TFR is below the Kerala level, and in five states (Himachal Pradesh, Punjab, Maharashtra, and Delhi); the TFR 
The Fertility Decline in India's Kerala State: A Unique Example of Below Replacement Fertility in a HIgh Fertility Country

has fallen to below or equal to the replacement level (2.1). Also, most of the urban areas of India have reached the replacement level of fertility. In this context, it is vital to carry out a comparative analysis of the factors that contributed to the recent fertility decline in these states along with the Kerala experience to answer the above question, and identify the factors that could help launch programs for hastening fertility decline in other states.

Part of the current economic prosperity in Kerala that has a per capita income comparable to the rich states in India may be attributable to the consequences of its demographic transition with low fertility achieved by 1990 . It is likely that the low fertility level will continue as more than $69 \%$ of women and three-fourths of men consider the ideal family size to be two children or less.

One of the notable adverse consequences of the low fertility however, is the current acute labor shortage in Kerala for manual work and in the service sector. As a result, Kerala, which has been an outmigrating state for a long time, has started importing workers from other states in India. A parallel development is the rising demographic growth imbalance among the state's three religious groups arising from the slow decline of fertility among the Muslim women. While Hindu and Christian women experienced a reduction in fertility below the replacement level by 1990 and continue at that level, the Muslim fertility level continues to be much higher than that of the other two groups. In 2005-2006, compared with Hindus and Christians, the average Muslim family size was higher by one child with a fertility rate of 2.5 , which is over $60 \%$ higher that of the Hindus and Christians. The fertility level of the Muslims has also not fallen since 1999, which maybe attributed to the low age at marriage, low family planning prevalence rates and the desire to have a larger family size among the Muslims. The socio- demographic, economic and political consequences of the continued high fertility among the Muslims concomitant with the very low fertility among the other two groups would be an interesting development with promising scope for new research. 


\section{Acknowledgements}

This is a revised version of the paper presented at the CPS Meeting in Ottawa, May 2009. I would like to thank Dr. Bali Ram for proposing me to prepare a paper on this topic, and Dr. Sabu Aliyar, Centre for Development Studies, Trivandrum, Kerala, India for providing some of the recent data and tables used in the paper. Thanks are also due to Marylou Mandell of the Georgia Student Finance Commission and David A. Swanson for reading the earlier version of the paper and their helpful comments. Responsibility for any errors rests with the author.

\section{End Note}

1. Currently India has 28 states, one national capital territory (Delhi) and six centrally administered territories.

\section{References}

Akers, D. 1967. The marriage squeeze. Demography 5(2): 907-924.

Basu, A. M. 1986. Birth control by asset less workers in Kerala: The possibility of a poverty induced fertility transition. Development and Change 17(2): 265-285.

Bhat, P. N. 2002. India's Changing Dates With Replacement Fertility: A Review of Recent Fertility Trends and Future Prospects. Paper presented at the United Nations Expert Group Meeting on Completing the Fertility Transition, Population Division, New York USA (March 2002).

Bhat, P. N. and S. I. Rajan. 1990. Demographic Transition in Kerala Revisited. Economic and Political Weekly 9(1-8): 1957-1990.

Bhat, P. N., S. I. Rajan and K. Navaneetham. 1989. Fertility and Family Planning in Pre and Post Emergency India: Towards an Explanation for Diverging Trends. Paper presented at the South Asian Conference on Population Trends and Family Planning, Organized by the Registrar General of India and East West Population Institute, Hawaii, New Delhi. 
The Fertility Decline in India's Kerala State: A Unique Example of Below Replacement Fertility in a HIgh Fertility Country

Bongaarts, J. 1978. A framework for analyzing the proximate determinants of fertility. Population and Development Review 4(1): 105-132.

Caldwell, J. C. 1979. Education as a factor in mortality decline: An examination of Nigerian data. Population Studies 33(3): 395-413.

Chesnais, J. C. 2000. The Future of French Fertility: Back to the Past, Or A New Implosion, in Below Replacement Fertility, Population Bulletin of the United Nations, New York (40/41): 212-233.

Coale, A. 1973. The Demographic Transition Reconsidered. Paper presented at the International Population Conference, Liege, Belgium: IUSSP, Vol. 1: 53-72.

Cleland J. and C. Wilson. 1987. Demand Theories of the Fertility Transition: An Iconoclastic View. Population Studies 4(1): 5-30.

Diamond, I., M. Newby and S. Varle. 1999. Female Education and Fertility: Examining the Links, in Critical Perspectives on Schooling and Fertility in the Developing World, edited by C. H. Bledsoe, et al. Washington, DC: National Academy Press, pp. 23-48.

Dyson, T. and M. Moore. 1983. On kinship structure, female autonomy and demographic behavior in India. Population and Development Review 9(1): 35-60.

Dyson, T. 2002. On the Future of Human Fertility in India. Paper presented at the United Nations Expert Group Meeting on Completing the Fertility Transition, Population Division, New York, USA (March 2002).

George, M. V. 1959. Differential Fertility in Kerala (Report for partial fulfillment of Post-Graduate Diploma) IIPS, Bombay.

George, M. V. 2000. Distinct Socio-Economic Developments and Demographic Transition in Kerala, India. Paper for the felicitation volume in honor of Professor K. Mahadevan, S.V. University, Tirupati.

CSP 37.3-4: 563-600 
Hajnal, J. 1953. Age at marriage and proportions marrying. Population Studies 7(2): 111-136.

Hobcraft, J. N., J. W. McDonald and S. O. Rustein. 1984. Socioeconomic factors in infant and child mortality: A cross national comparison. Population Studies 38(2): 193-224.

Jiang, Z. 2000. The Fertility Transition and Prospects in China and Other Eastern Asian Countries, in Below Replacement Fertility, Population Bulletin of the United Nations, New York (40/41): 197-217.

Kapur, P. N. 1989. Recent Decline in Birth Rate in India and Its Relationship with Contraceptive Prevalence, in Population Transition in India, edited by S. N. Singh, M. K. Premi, P. S. Bhatia and A. Bose. Delhi: B.R. Publishing Corporation. Vol. 1: 105-119.

Krishnan, T. N. 1976. Demographic transition in Kerala: Facts and factors. Economic and Political Weekly 11(31-33): 1203-1224.

Manorama Year Book. 2009. Malayala Manorama Press, Kottayam, Kerala, India.

Mencher, J. 1980. The lesson and non-lessons of Kerala: Agricultural laborers and poverty. Economic and Political Weekly 15(41-43): 1781-1802.

Nag, M. 1989. Alternative Routes of Fertility and Mortality Decline: A Study of Kerala and Punjab, in Population Transition in India, edited by S. N. Singh, M. K Premi, P. S. Bhatia and A. Bose. Delhi, India: BR Publishing Corp., Vol. 1: 143-157.

National Family Health Survey (NFHS-1, 1992-93; NFHS-2, 1998-99; and NFHS-3, 2005-06). International Institute for Population Sciences (IIPS), Mumbai and Macro International.

Rajan, S. I. and K. C. Zachariah 1997. Long Term Implications of Low Fertility in Kerala. Paper presented at a Seminar at the Center for Development Studies, Thiruvananthapuram, Kerala, India. 
The Fertility Decline in India's Kerala State: A Unique Example of Below Replacement Fertility in a HIgh Fertility Country

Ratcliffe, J. 1978. Social justice and demographic transition: Lessons from India's Kerala state. International Journal of Health Services 8(1): 123-144.

Shryock, H. S. and J. S. Siegel. 1971 The Methods and Materials of Demography. Bureau of the Census, U. S. Government Printing Office, Washington, D. C. p. 295.

Stokes, S. C. 1995. Explaining the demographic transition: Institutional factors in fertility decline. Rural Sociology 60(1): 1-22.

United Nations. 1990. Socio-Economic Development and Fertility Decline: A Review of Some Theoretical Approaches. Population Division, Department of International and Social Affairs, New York.

United Nations. 2000. Below Replacement Fertility, Population Bulletin of the United Nations, New York (40/41): 197-217.

United Nations. 2005. World Population Prospects: the 2004 Revision, Vol. 1, Comprehensive Tables. Population Division, New York.

Zachariah, K. C. 1984. The Anomaly of the Fertility Decline in India's Kerala State: A Field Investigation. Staff Working Paper No. 700, The World Bank, Washington DC.

Zachariah, K. C. and R. S. Kurup. 1984. Determinants of Fertility Decline in Kerala, in Essays on the Contemporary Population, edited by Tim Dyson and Nigel Crook. New York: South Asian Publishers Ltd., pp. 51-71.

Zachariah, K.C., S. I. Rajan, P.S. Sarma, K. Navaneetham, P.S.G. Nair, and U. S. Misra. 1992. Demographic Transition in Kerala in the 1980s, Results of a Survey in Three Districts. Centre for Development Studies, Thiruvananthapuram, Kerala, India.

Zachariah, K.C., K.P. Kannan, and S. I. Rajan (eds.). 2002. Kerala's Gulf Connection, CDC Studies on International Labor Migration from Kerala State, India. Center for Development Studies, Thiruvananthapuram, Kerala, India. 